\title{
Variation in Wood Properties and Growth in Some Clones of Populus deltoides Bartr. ex Marsh
}

\author{
P. K. Pande \\ Wood Anatomy Discipline, Botany Division, Forest Research Institute, Dehradun, India. \\ Email: pandep123@rediffmail.com
}

Received October $27^{\text {th }}, 2010$; revised November 27 $7^{\text {th }}, 2010$; accepted January $11^{\text {th }}, 2011$.

\begin{abstract}
The present paper deals with within ramet radial, intra- and inter-clonal variations in the wood element's dimensions and specific gravity of 10 clones of Populus deltoides Bartr. ex Marsh. The growth parameters namely ramet height and DBH were also considered for the study. Study material was collected from the 10 clones of Populus deltoids raised by WIMCO Plantations Ltd. at Rudrapur (Udhamsingh Nagar), India. Three clones were parent viz. G48, S7C8 (female) and G3 (male). Other clones represent hybrids of F1 generation. Inter- and intra-clonal variations were significant for all the wood traits except vessel element length for intra-clonal variations. Within ramet variations due to radial location were significant for fiber length and specific gravity with increasing trend from pith to periphery. Interaction of clone*replication was also significant for all the wood traits. Variations were significant for the DBH for the clones. Fiber length and specific gravity was significantly higher in female while wall thickness and vessel element length was in male clones $(P<0.01)$. Female parents (G48 and S7C8) showed higher fiber length and specific gravity than of the male parent (G3) while vessel element diameter and wall thickness was higher in male parent (G3). Fiber length was higher in offspring than the parent clones which may be the reflection of hybrid vigor for the trait. The clones of F1 offspring followed the similar patterns for the other wood traits as in the parent clones. Hierarchical cluster analysis showed that W/A 39 (male) and W 39 (female) clones of F1 generation were highly divergent than of the other clones.
\end{abstract}

Keywords: Fiber Length, Specific Gravity, Vessel Element Length Wall Thickness, Wood Variations

\section{Introduction}

Wood quality and growth are two important parameters need to be analyzed for the utilization and development of new clones. Populus deltoides Bartr. ex Marsh is grown under different forestry programs as clonal plantations to ensure the genetic superiority for better growth and superior wood quality.

The variability in wood anatomical characteristics has profound influence on the properties of wood [1,2]. Features of interest in this connection include cell size, proportion and arrangements of different elements of secondary xylem and specific gravity. The general pattern of variation in wood element dimensions is found not only within a species but also observed within a tree by many a worker [3-5].

Variations in the dimensions of wood elements and specific gravity both within tree and among the clones have come under close scrutiny in recent years. There are reports available on the variation in wood anatomical and other properties in different clones of Populus elsewhere
[6-9].

Populus deltoides showed intra- and inter-clonal variability in wood traits [8-11]. So, the close scrutiny of different clones is essential to understand the variability trends for different wood traits in the species. The wood elements dimensions and specific gravity are the important parameters to be assesses in terms of their within ramet, intra- and inter-clonal variability so that clones having desired wood traits can be used for the development of new clones. Hence, the present paper deals with the, inter- and intra-clonal and within ramet radial variations in wood anatomical parameters and specific gravity of 10 clones of Populus deltoides.

\section{Materials and Methods}

\subsection{The Experimental Site}

Study site was located at Rudrapur (Udhamsing Nagar), Uttarakhand, India. It is situated at around $28^{\circ} \mathrm{N}$ latitude; $78^{\circ} \mathrm{E}$ longitude and at the altitude of $200 \mathrm{~m}$ asl (Figure 1). The annual rainfall was $1200 \mathrm{~mm}$; of which $88 \%$ occurs 
during June-August. The average maximum summer temperature (April-June) was $36.7^{\circ} \mathrm{C}$ and average minimum temperature (December-February) was $7.5^{\circ} \mathrm{C}$ (20052006). The soil of the site was sandy loam.

\subsection{Planting Material}

The growth parameters namely ramet height and $\mathrm{DBH}$ were measured for each individual before the collection of wood samples. Study material was collected from the 10 clones of Populus deltoids raised by WIMCO Plantations Ltd. at Rudrapur (Udhamsingh Nagar), India. Three clones were parent viz. G48, S7C8 (female) and G3 (male). Other clones represent hybrids of F1 generation. The year of plantation was February, 2000 and the month of collection of samples was October, 2007. The soil of the plantation site was sandy loam. The clones were raised in Randomized Block Design. The spacing of clonal trial was $5 \times 5 \mathrm{~m}$. The details of clones are given in Table 1.

\subsection{Sampling}

Wooden cores were extracted from three replicate ramets

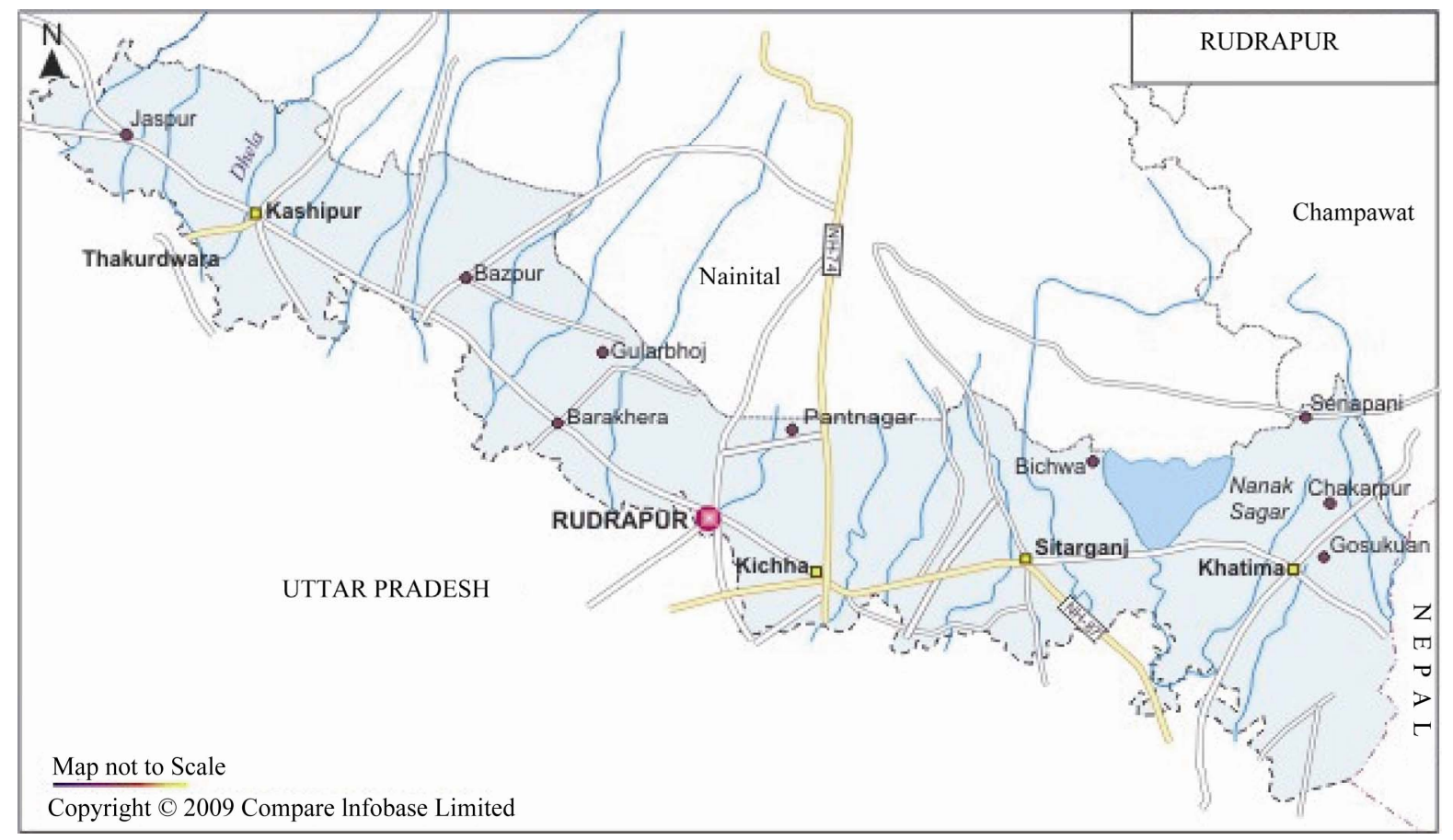

Figure 1. Location map of the site.

Table 1. Wood ( $\mu \mathrm{m})$ and growth traits of Populus deltoides clones.

\begin{tabular}{|c|c|c|c|c|c|c|c|c|c|c|c|c|c|c|c|c|}
\hline Clone & Parents & Generation & Sex & FL & SD & FD & SD & WT & SD & VL & SD & VD & SD & SG & $\begin{array}{l}\text { DBH } \\
\text { (cm) }\end{array}$ & $\begin{array}{c}\text { Height } \\
\text { (m) }\end{array}$ \\
\hline Kranti & $\mathrm{G} 48 * \mathrm{G} 3$ & $\mathrm{~F} 1$ & $\mathrm{~F}$ & 1048.7 & 145.7 & 27.8 & 4.3 & 4.8 & 0.92 & 560.2 & 101.2 & 104.4 & 19.8 & 0.333 & 24.0 & 16.5 \\
\hline S7C8 & $\mathrm{P}$ & $\mathrm{P}$ & $\mathrm{F}$ & 1140.0 & 161.0 & 25.7 & 4.3 & 4.5 & 0.92 & 560.2 & 125.7 & 103.1 & 26.3 & 0.368 & 23.4 & 16.1 \\
\hline G48 & $\mathrm{P}$ & $\mathrm{P}$ & $\mathrm{F}$ & 1161.8 & 169.8 & 25.7 & 4.4 & 4.5 & 1.07 & 552.5 & 113.8 & 96.1 & 20.7 & 0.423 & 23.4 & 16.6 \\
\hline W. 39 & $\mathrm{G} 48 * \mathrm{G} 3$ & $\mathrm{~F} 1$ & F & 1229.3 & 131.3 & 25.3 & 2.4 & 3.9 & 0.42 & 572.3 & 88.5 & 106.7 & 18.6 & 0.420 & 31.8 & 21.5 \\
\hline Bahar & G48*G3 & $\mathrm{F} 1$ & $\mathrm{~F}$ & 1190.0 & 161.1 & 24.8 & 3.4 & 3.9 & 0.70 & 531.9 & 107.8 & 96.3 & 18.6 & 0.419 & 26.2 & 18.3 \\
\hline Udai & G48*G3 & $\mathrm{F} 1$ & M & 1202.1 & 182.1 & 25.9 & 3.9 & 4.5 & 0.99 & 539.3 & 107.8 & 95.3 & 18.5 & 0.383 & 25.1 & 17.9 \\
\hline W. 22 & G48*G3 & F1 & M & 1136.3 & 133.7 & 26.2 & 3.2 & 4.3 & 0.89 & 558.0 & 99.5 & 109.5 & 19.1 & 0.367 & 28.5 & 19.6 \\
\hline G3 & $\mathrm{P}$ & $\mathrm{P}$ & M & 1048.2 & 201.1 & 28.1 & 5.4 & 5.0 & 1.36 & 559.4 & 142.3 & 108.4 & 31.2 & 0.366 & 17.6 & 15.3 \\
\hline Сp82-5-1 & S7C $8 * G 3$ & F1 & M & 1049.0 & 160.2 & 23.3 & 4.3 & 4.2 & 1.11 & 558.2 & 115.6 & 105.1 & 29.5 & 0.349 & 17.4 & 15.9 \\
\hline W-A/39 & G48*G3 & F1 & M & 1057.0 & 191.6 & 23.7 & 4.6 & 3.9 & 1.10 & 597.8 & 133.6 & 104.3 & 23.0 & 0.379 & 21.3 & 23.9 \\
\hline
\end{tabular}

Note: FL = fiber length, FD = fiber diameter, WT = wall thickness, VL = vessel element length, VD = vessel element diameter, SG = specific gravity, SD = standard deviation, DBH = Diameter at breast height. 
of each of the 10 clones at $3.17 \mathrm{~m}$ height from the base from the north direction. Each core was divided into three pith to periphery locations viz. inner, middle and outer. In total 90 samples were considered for anatomical studies viz. fiber length, fiber diameter, wall thickness, vessel element length, vessel element diameter and specific gravity. Standard laboratory methods were followed for the preparation of macerations. Wooden cores were fragmented into small pieces and put into the test tube. The material was macerated with $50 \% \mathrm{HNO}_{3}$ and a pinch of $\mathrm{KClO}_{3}$. The macerated wood elements were thoroughly mixed and were spread on a glass slide and observations were taken under compound microscope [12]. Measurements for fiber length, fiber diameter, wall thickness, vessel element length and vessel element diameter were taken from the macerated wood. Twenty five unbroken cells were sampled for the measurement of each parameter [13]. Basic density of core samples was determined as the ratio of oven dry weight vs. green volume. The green volume was determined by water displacement method. Specific gravity is the ratio of the density of the core sample vs. density of water [12].

\subsection{Statistical Analysis}

The data so obtained were statistically analyzed using SPSS 10. Multivariate analysis was done to test the within ramet radial and intra- and inter-clonal variations. Hierarchical cluster analysis was done with SPSS 10 for wood anatomical properties and specific gravity and growth parameters together using "Squared Euclidean Distance" method. The hierarchical grouping develops a relationship between clones that are maximally similar for specified traits. Each of the clones is genetically different from another. However, the extent of difference might be varying to a certain degree. Thus, during clustering number of clones may vary from one to the total number of clones used. To optimize the number of cluster, a cut of line was derived on the dendrogram that was close to $1 / 5^{\text {th }}$ of the value. Five numbers of clusters were developed based on the information.

\section{Result and Discussion}

Tables 1-5 show results obtained on the various aspects of study.

The range for fiber length for different clone was 1048.2 (G3) - 1229.3 $\mu \mathrm{m}$ (W-39); 23.3 (Cp82-5-1) - 28.3 $\mu \mathrm{m}$ (G3) for fiber diameter; 3.9 (W-39) - 5.0 (G3) $\mu \mathrm{m}$ for wall thickness; 531.9 (Bahar) - 597.8 (W/A 39) $\mu \mathrm{m}$ for vessel element length; 96.1 (G48) - 109.5 (W 22) 109.5 for vessel element diameter and for 0.333 (Kranti) 0.423 (G48) specific gravity. The average ramet height (m) of the clone ranged from 15.3 (Cp82-5-1) - 23.9 (W/A 39) m while DBH (cm) ranged from 17.4 (Cp82-

\section{5-1) - $28.5 \mathrm{~cm}$ (W 22) (Table 1).}

Table 2 shows multivariate analysis of wood anatomical variations of different clones of Populus deltoides. Inter- and intra-clonal variations were significant for all the wood traits except vessel element length for intra-clonal variations. Within-ramet variations due to radial location were significant for fiber length and specific gravity. Interaction of clone*replication was also significant for all the wood traits. Variations were significant for the DBH for the clones. Significant differences in average specific gravity of different clones of different species of Populus were reported [6,8]; in Tectona grandis [14] and in Eucalyptus tereticornis Sm. [15, 16]. In contrary, non-significant radial and directional variations in specific gravity and fiber length in different clones of Dalbergia sissoo were reported by Pande and Singh [17], however these variations were significant due to height of the ramet. Significant inter-tree variation in specific gravity of Dalbergia sissoo was reported by Pande [18] and in Lucanea leucocephala by Pande et al. [19]. Similarly, significant differences among the different clones of different species in average fiber length were reported by many a worker $[6,8,9,15,17,20]$. Interclonal variation in vessel element dimensions in Dalbergia sissoo was reported by Pande and Singh [17]; in Populus deltoides by Chauhan et al. [8] and in Tectona grandis by Rao and Shashikala [21]. Significant intraclonal variations were reported by Gautam [10] in L-34 clone of Populus deltoids while within-ramet radial variation was significant for specific gravity with the increasing trend from pith to periphery and related to the cambial age of the wood. The increasing trend from pith to periphery for average fiber length and specific gravity was also noticed in the present study. Within-ramet non-significant radial variations for most of the wood traits showed no impact of age on the dimensions of wood elements and regulate mostly homogeneous wood properties within the ramet. Intra-clonal significant variations indicated that differential wood properties might be expected from the population of the same clone.

Fiber length and specific gravity was significantly higher in female while wall thickness and vessel element length was in male clones $(\mathrm{P}<0.01)$. Female parents (G48 and S7C8) showed higher fiber length and specific gravity than of the male parent (G3) while vessel diameter and wall thickness was higher in male parent (G3). Fiber length was higher in offspring than the parent clones which might be the reflection of hybrid vigor for this trait. The clones of F1 offspring and parents followed the similar pattern for the other wood traits (Table 3).

Hierarchical cluster analysis was done using "Squared Euclidean Distance" for all the 10 clones considering all 
Table 2. ANOVA for wood traits of different clones of Populus deltoids.

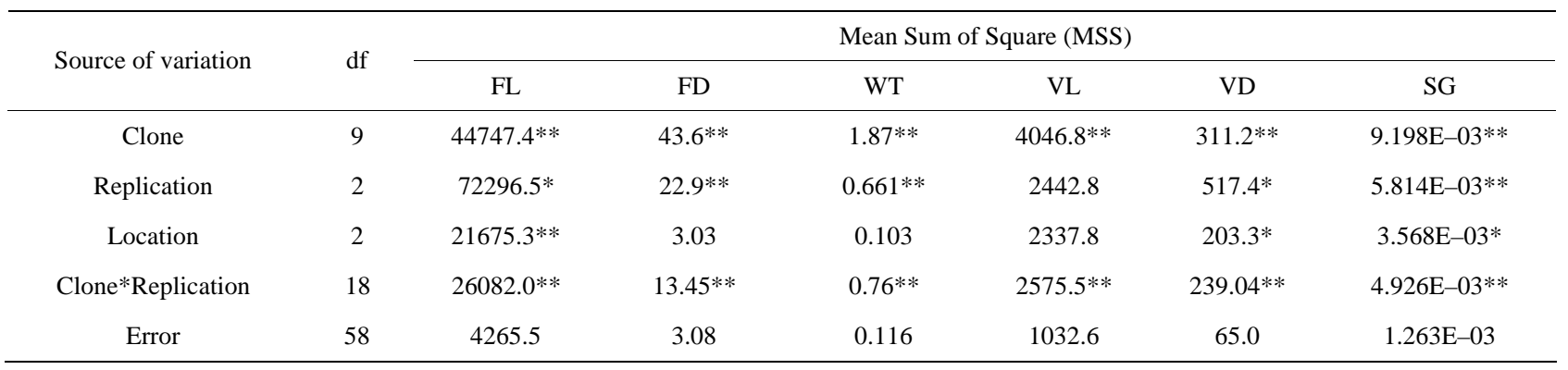

Table 3. Mean wood traits as per the sex.

\begin{tabular}{cccccc}
\hline \multirow{2}{*}{ Dependent Variable } & Sex & Mean $(\boldsymbol{\mu m})$ & \multicolumn{3}{c}{ Std. Error } \\
\cline { 4 - 6 } & & & 95\% Confidence Interval & Lower Bound & Upper Bound \\
\hline FL & Female & 1148.9 & 16.6 & 1115.76 & 1182.1 \\
& Male & 1103.4 & 16.6 & 1070.23 & 1136.6 \\
FD & Female & 25.4 & 0.41 & 24.60 & 26.2 \\
WT & Male & 25.8 & 0.41 & 25.02 & 4.4 \\
Female & 4.2 & 0.09 & 4.03 & 4.7 \\
VL & Male & 4.5 & 0.09 & 4.32 & 5 \\
VD & Female & 548.1 & 5.56 & 537.02 & 573.466 \\
& Male & 562.378 & 5.562 & 551.289 & 103.647 \\
SG* & Female & 100.511 & 1.573 & 97.376 & 104.358 \\
& Male & 101.222 & 1.573 & 98.087 & 0.406 \\
\hline
\end{tabular}

Note: $*=$ No unit.

Table 4. Constitution of different clusters.

\begin{tabular}{ccc}
\hline Cluster Number & No. of clones in the cluster & Clone number and sex \\
\hline $\mathbf{1}$ & 3 & G3 (Male), Cp82-5-1 (Male), Kranti (Female) \\
$\mathbf{2}$ & 1 & W-A/39 (Male) \\
$\mathbf{3}$ & 3 & S7C8 (Female), W 22 (Female), G 48 (Female) \\
$\mathbf{4}$ & 2 & Bahar (Female), Udai (male) \\
$\mathbf{5}$ & 1 & W 39 (male) \\
\hline
\end{tabular}

Table 5. Mean value of wood element's dimensions $(\mu \mathrm{m})$ and specific gravity.

\begin{tabular}{|c|c|c|c|c|c|c|c|c|}
\hline Parameters/Cluster Number & FL & FD & WT & VL & VD & SG & DBH (cm) & Height (m) \\
\hline 1 & 1048.6 & 26.37 & 4.67 & 559.27 & 105.97 & 0.349 & 19.67 & 15.9 \\
\hline 2 & 1057.0 & 23.7 & 3.9 & 597.8 & 104.3 & 0.379 & 21.3 & 23.9 \\
\hline 3 & 1146.03 & 25.87 & 4.43 & 556.8 & 102.9 & 0.386 & 25.1 & 17.43 \\
\hline 4 & 1196.05 & 25.35 & 4.2 & 536.6 & 95.8 & 0.401 & 26.8 & 18.1 \\
\hline 5 & 1229.0 & 25.3 & 3.9 & 572.3 & 106.7 & 0.420 & 31.8 & 21.5 \\
\hline
\end{tabular}




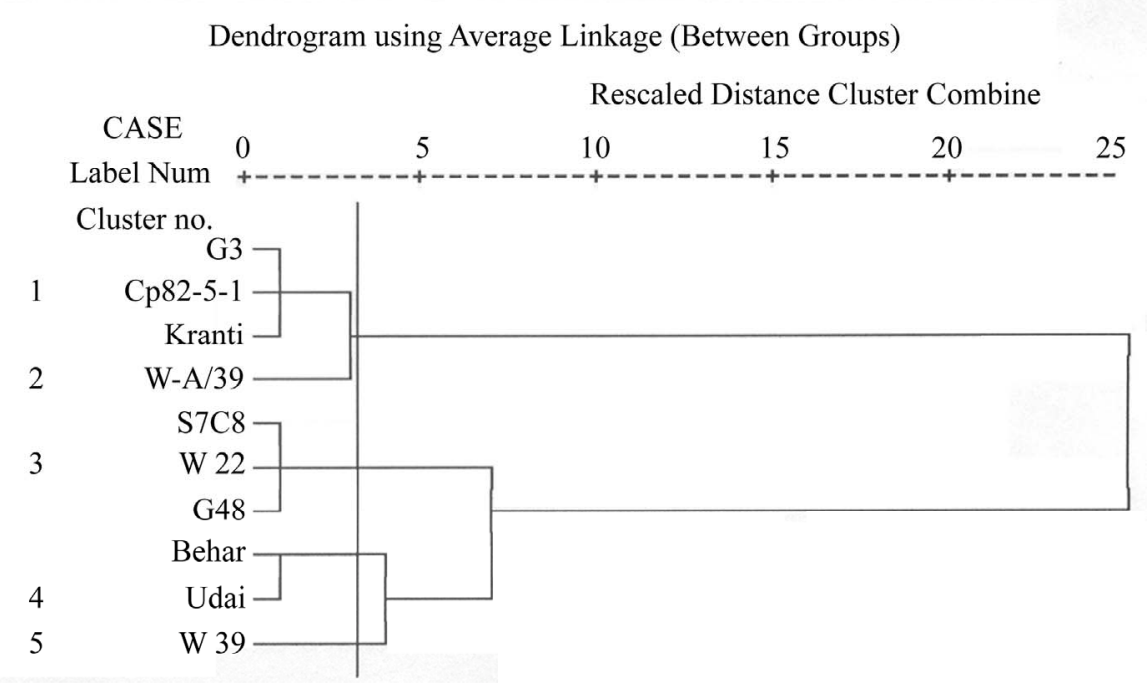

Figure 2. Dendrogram using acerage linkage (between the groups) for the different clones cl of Populus deltoids.

the wood and growth traits. Dendrogram was prepared using Average Linkage (between groups). In the study, 10 clones were grouped into 5 clusters at 5 rescaled distance cluster combine (Figure 2). The constituents of different clusters were given in Table 4. Cluster 1 and 3 were the largest clusters having 3 clones in each whereas cluster numbers 2 and 5 have only one clone each. Cluster 5 was the highly divergent from other clusters having the clone W39.

The mean values of different wood traits for different clusters are given in Table 5. Cluster 5 showed highest values for wood traits viz. fiber length, vessel element diameter and specific gravity and growth parameter viz. DBH while fiber diameter and specific gravity were higher in cluster 1 . Ramet height was higher in cluster 2. Lower values were represented by cluster 2 for fiber dimensions while vessel dimensions by cluster 4 . Lower specific gravity was shown by cluster 1 . Lower growth traits were represented by cluster 1 (Table 5).

Genetic divergence is most effective tool to identify the parents for hybridization [22]. Selection for both female and male parents from two divergent clusters is important to develop hybrids for new clones. Clusters 2 and 5 were the divergent clusters for male and female parents respectively. Cluster 2 has one male clone i.e. W/A 39 which was highly divergent from the clones clustered in cluster 1 at 4 rescaled distance cluster combine. In the same way, cluster 5 has the female clone $\mathrm{W}$ 39 which was divergent from other clones at 5 rescaled distance cluster combine. Since, clones in cluster 2 and 5 were highly divergent from other clones so used in number of combinations as parents to develop new hybrids. These clones can be used for establishing clonal seed orchard for immediate gain in view of their high diver- gent nature

Though, clonal strategy is alleged to offer narrow genetic base yet vegetative propagation has strongly recommended [23-25]. Populus deltoides is propagated through clones. So development/selection of new clones in view of their desired wood properties is of utmost importance for the products. In this study, the highly divergent male clone (W/A 39) and female clone (W39) are important and should be used in number of combinations for developing new hybrids of desired wood traits to develop new clones.

\section{Acknowledgements}

I Acknowledge to the Director, Forest Research Institute, Dehradun (India) for providing necessary facilities during the work and Dr. R. C. Dhiman, WIMCO Seedlings Ltd. Rudrapur, India for providing the material. Author is also thankful to Mr. G. S. Bisht, Research Assistant, Wood anatomy Discipline, Forest Research Institute, Dehradun (India) for laboratory-assistance and Mr. J. N. Gandhi of WIMCO Seedlings Ltd. Rudrapur (India) for field assistance.

\section{REFERENCES}

[1] H. E. Dadswell, "Tree Growth Characteristics and Their Influence on Wood Structure and Properties," Proceedings of 7th British Commonwealth Forestry Conference, CSIRO, Canberra, 1957, p. 19.

[2] J. Burley and R. R. Palmer, "Pulp and Wood Densitometric Properties of Pinus caribaea from Fiji," C.F.I. Occasional Paper No. 66, 1979.

[3] J. M. Dinwoodie, "Tracheid and Fiber-Length in Timber. A Review of Literature,” Forestry, Vol. 34, 1961, pp. 124-144. 
[4] B. S. S. Rao and R. V. Rao, "Variation in Length of Vertical Elements within One Tree of Betula pubercens Ehrh," Journal of Indian Academy of Wood Science, Vol. 9, No. 2, 1978, pp. 105-110.

[5] P. K. Pande, R. V. Rao, S. P. Agrawal and M. Singh, "Variation in the Dimensions of Trachied Elements of Pinus caribaea var. Bahamensis," Journal of Tropical Forest Products, Vol. 1, No. 2, 1995, pp. 117-123.

[6] J. E. Phelps, J. G. Isebrands and D. Jowett, "Raw Material Quality of Short Rotation Intensively Cultured Populus Clones. A Comparison of Stem and Branches Properties at Three Species,” IAWA Journal, Vol. 3, No. 3-4, 1982, pp. 193-200.

[7] A. Kaubaa, A. E. Hernandez, M. Beaudoin and J. Poliquin, "Interclonal, Intra-Clonal and within Tree Variationin Fiber-Length of Popular Hybrid Clones," Wood and Fiber Science, Vol. 30, No. 1, 1998, pp. 140-147.

[8] L. Chauhan, R. D. Raturi and S. Gupta, "Studies on anatomical variations in different clones of Populus deltoides,” Indian Forester, Vol. 125, 1999, pp. 526-532.

[9] L. Chauhan, S. Gupta, R. C. Madhwal, R. Pandey and M. Pal, "Interclonal, Intraclonal and within Tree Variation in Wood Parameters of Different Clones of Populus deltoides,” Indian Forester, Vol. 127, No. 7, 2001, pp. 777784.

[10] P. Gautam, "Multilocational Trials of Micro-Propa- Gated L-34 Clone of Populus deltoides Bartr. ex Marsh: Analysis of Wood Anatomical Properties and Growth,” Ph.D Thesis, Forest Research Institute University, Dehradun, 2010.

[11] P. K. Pande and R. C. Dhiman, "Variations in Wood Tratis in Micro and Macro Propagated Plantation Woods of Populus deltoides Bartr. ex Marsh,” Advances in Biosciences and Biotechnology, Vol. 1, 2010, pp. 263-275. doi:10.4236/abb.2010.14035

[12] S. K. Purkayastha, S. P. Agrawal, P. Farooqui, R. D. Tandon, L. Chauhan and N. Misra, "Evaluation of Wood Quality of Eucalyptus Plantations in Various States," Final Technical Report, PL 480 Project no Inn FS-66, 1979-1980, p. 85.

[13] IAWA, "Committee List of Microscopic Features for Hardwood Identification,” IAWA Bulletin, Vol. 10, 1989, pp. 201-332.

[14] T. Okuyama, H. Yamamoto, I. Wahyudi, Y. S. Hadi and K. M. Bhat, "Some Wood Quality Issues in Planted Teak,” International Conference on Quality Timber Products of Teak from Sustainable Forest Management, KFRI, Kerala, 2-5 December 2003, p. 21.
[15] R. V. Rao, S. Shashikala, P. Sreevani, V. Kothiyal, C. R. Sharma and P. Lal, "Within Tree Variation in Anatomical Properties of Some Clones of Eucalyptus tereticornis Sm," Wood Science Technology, Vol. 36, No. 3, 2002, pp. 271-285. doi:10.1007/s00226-002-0139-3

[16] P. K. Pande, “Assessment of the Performance of Different Clones of Dalbergia Sissoo and Eucalyptus tereticornis on the Basis of Wood Quality under Different Farm Forestry Programs," Final Technical Report, ICFRE, Dehradun, 2005.

[17] P. K. Pande and M. Singh, "Intraclonal, Inter-Clonal and Single Tree Variations of Wood Anatomical Properties and Specific Gravity of Clonal Ramets of Dalbergia sissoo Roxb," Wood Science Technology, Vol. 39, No. 5, 2005, pp. 351-366. doi:10.1007/s00226-004-0273-1

[18] P. K. Pande, “Assessment of the Wood Quality Parameter in Seed Raised Plantations of Different Diameter Classes of Dalbergia sissoo Roxb,” FRI-299/Bot-45, FTR submitted to ICFRE, 2008, pp 120-126.

[19] P. K. Pande, S. Naithani, V. Kothiyal, Mohanta, S. S., N. Juyal and R. Rawat, "Intra and Inter Tree Variations in Physico-Chemical and Wood Anatomical Properties of Leucaena leucocephala (Lam.) De Wit,” Indian Forester, Vol. 134, No. 5, 2008, pp. 622-632.

[20] W. K. Murphey, T. W. Bowersox and P. R. Blankenhorn, "Selected Wood Properties of Young Populus Hybrid," Wood Science, Vol. 11, No. 4, 1979, pp. 236-267.

[21] R. V. Rao and S. Shashikala, “Assessment of Growth Rate, Basic Density and Heart Wood Content in Selected Teak Clones of CSO, Thithimathi in Karnataka State, India,” International Conference on Quality Timber Products of Teak from Sustainable Forest Management, KFRI, Kerala, 2-5 December 2003, p. 57.

[22] G. M. Bhatt, “Comparison of Various Methods of Selecting Parents for Hybridization in Common Bread Wheat (Triticum aestivum)," Australian Journal Agriculture Research, Vol. 24, No. 4, 1973, pp. 457-484. doi:10.1071/AR9730457

[23] E. Camphinhos and Y. K. Ikemori, "Mass Production of Eucalyptus Species by Rooting Cuttings," Proceedings IUFRO symposium Genetic Improvement and Production of Fast Growing Trees, Sao Pede Sao Paulo, 1980, p. 16.

[24] M. R. Ahuja and W. J. Libby, “Clonal Forestry I: Genetics and Biotechnology," Springer-Verlag, New York, 1993 a, p. 227.

[25] M. R. Ahuja and W. J. Libby, "Clonal Forestry II: Genetics and Biotechnology,” Springer-Verlag, New York, 1993 b, p. 240. 